\title{
90-Days Repeated Dose Oral Toxicity Study on Majoon-e-Nisyan
}

\author{
Masud Shaikh ${ }^{1}$, Syed Shoeb Ahmed ${ }^{1}$, Mohd Urooj ${ }^{1}$, Uzma Viquar, \\ Munawwar Husain Kazmi ${ }^{1}$, Gulam Mohammed Husain ${ }^{1^{*}}$ \\ ${ }^{1}$ Pharmacology Research Laboratory, National Research Institute of Unani Medicine for Skin \\ Disorders, Hyderabad - 500038, India
}

( ${ }^{\star}$ Corresponding Author Email: gmhusain@gmail.com)

Keywords: Majoon-e-Nisyān, Toxicity Study, Hematology, Biochemical, Histopathology.

\begin{abstract}
Majoon-e-Nisyan (MJN) is a polyherbal semisolid compound formulation. Its description is present in various Unani literatures. It is used in Unani medicine for its therapeutic efficacy against amnesia. There is no report regarding its safety on long term administration. Therefore, toxicological evaluation of MJN is carried out in rats. Majoon-e-Nisyan was subjected to 90-days repeated oral dose toxicity studies as per OECD guide line 408. Wistar rats were treated at three dose levels i.e., 500, 1000 and $2000 \mathrm{mg} / \mathrm{kg}$ bw and one vehicle treated group. MJN and vehicle were orally administered daily for 90 days and animal were observed for clinical signs of toxicity, mortality, body weight and feed consumption. On completion of 90-days, blood samples were collected and analyzed for hematology and biochemistry. Necropsy was performed on all survived animals and vital organs were collected and subjected to histopathology. No post dose adverse effect was reported on rats after oral administration of MJN for 90 days. No incidence of mortality was reported in MJN treated male and female rats at all tested dose levels. No abnormal clinical signs were observed in MNJ treated animals at 500, 1000 and $2000 \mathrm{mg} / \mathrm{kg}$ bw as compared to animals of control group. No significant changes were observed in biochemistry, hematology and histopathological examination. No incidence of mortality, adverse changes in clinical signs of toxicity or body weight gain of rats was noted. No changes in clinical chemistry, hematology, and histopathology were observed in MJN-treated or control group. Therefore, NOAEL for MJN may be considered more than $2000 \mathrm{mg} / \mathrm{kg}$ bw in rats.
\end{abstract}

\section{Introduction}

The management of amnesia is based on the underlying cause in conventional medicine. In general, memory loss may be improved with cognitive rehabilitation techniques. The pharmacological intervention is commonly attained by acetylcholinesterase (AChE) inhibitors such as tacrine and donepezil which exhibit various side effects such as diarrhea, headache, insomnia, nausea, vomiting, abdominal pain, weight loss, and weakness [1]. Hence, there is a need for safe and effective treatment for amnesia through the traditional Unani method of therapy. In Unani system of medicine, Nisyān is the possible equivalent term for Amnesia [2]. Nisyān is derived from the word "Naseen" meaning forgetfulness [2]. The patient is unable to recall the past incidents, whether in awake or in sleep state [3]. There are various single and compound drugs are mentioned in classical Unani literature for treatment of Nisyān (Amnesia) [4]. MJN is a Pharmacopoeial Unani formulation that has been documented to be effective in Nisyān [5-7]. MJN consists of Kundur (Boswelia serrata), Sa'd Koofi (Cyperus rotundus), Waj (Acorus calamus), Filfil Siyah (Piper nigrum) and Zanjabeel (Zingiber officinale). Though MJN is used clinically in Unani medicine, the long-term safety of this formulation is not documented in literature. Hence, the present study is designed to evaluate pre-clinical safety study of $\mathrm{MJN}$ in rats.

\section{Materials and Methods}

\subsection{Experimental Animals}

Wistar rats $(100 \pm 20 \mathrm{~g}$, about 6 weeks old) were procured from Edara Research Foundation, Hyderabad, India. The selected females were nulliparous and non-pregnant. Rats were housed in 
polycarbonate cages in the air conditioned room maintained at the temperature of $22^{\circ} \mathrm{C} \pm 3{ }^{\circ} \mathrm{C}$ and relative humidity of 30-70\%, with a 12:12 h light/dark illumination cycle. CPCSEA guidelines [8] of laboratory animal care were followed throughout the experiment. Protocol of the study was approved by the Institutional Animals Ethics Committee vide Protocol No CRIUM/IAEC/2017/01/P09. Animals were acclimatized to the laboratory conditions for one week before using them for experiment. Animals were maintained with free access to pellet feed (SDS Diet) and drinking water, unless stated in the protocol.

\subsection{Dose Selection}

Therapeutic dose of MJN is $5.00 \mathrm{~g}$ once a day [9]. Rat doses were back calculated on the basis of body surface area conversion method from human dose [10]. For 90-day repeated dose oral toxicity on MJN, three dose groups were included i.e., Therapeutic Equivalent Dose (TED) for $5.00 \mathrm{~g}$ human dose (equivalent dose in rats is $\sim 500 \mathrm{mg} / \mathrm{kg}$ bw per day) and $1,000 \mathrm{mg} / \mathrm{kg}$ bw per day (i.e., about 2 times of TED) and $2000 \mathrm{mg} / \mathrm{kg}$ bw per day (i.e., 4 times of TED).

\subsection{Experimental Design}

The 90-day repeated dose oral toxicity study was performed as per the Organisation for Economic Co-operation and Development (OECD) test guideline-408 method [11]. Male and female Wistar rats were randomly divided into four groups with 20 animals (10 males +10 females) in each group.

\subsection{Drug / Formulation}

A suspension of $\mathrm{MJN}$ in $0.3 \%$ aqueous carboxymethyl cellulose $(\mathrm{CMC})$ was freshly prepared every day. The drug was orally administered as an aqueous suspension at the maximum volume of $2 \mathrm{~mL} / 100 \mathrm{~g} / \mathrm{bw}$. The control animals were administered with vehicle only (i.e., $0.3 \% \mathrm{CMC}$ ). MJN was administered at dose levels of $500 \mathrm{mg} / \mathrm{kg}, 1000 \mathrm{mg} / \mathrm{kg}$ bw and $2000 \mathrm{mg} / \mathrm{kg}$ bw once daily for 90 consecutive days at same time each day to minimize variations.

\subsection{Observations and Examinations}

Experimental rats were observed for mortality and morbidity twice a day, throughout the study duration. Detailed clinical observations (i.e., functional observation parameters) were made periodically to detect any signs of toxicity, at the same time (1h after vehicle or drug administration). Body weight of the animals was recorded once in a week. Average feed consumption for both sexes were recorded at weekly interval by weighing the amounts of feed given to a cage group and weighing the leftover feed on the next day. Assessment of motor activity was conducted during 13th week using computerized rotarod apparatus (Ugo Basile, Italy).

At the end of treatment period, the overnight fasted (water provided ad libitum) rats were anesthetized with isoflurane inhalation (EZ Anaesthesia system; Model-1339), blood samples were collected by retro-orbital puncture for hematological and biochemical analysis.

Hemoglobin ( $\mathrm{Hb}$ ), red blood cell count (RBC), differential white blood cell count (WBC), hematocrit (HCT) and platelet count (PLT) were analyzed using automated haematology analyzer (Swelab, Model-920EO+). Serum biochemical parameters such as glucose, alanine transaminase (ALT), aspartate transaminase (AST), alkaline phosphatase (ALP), total bilirubin, creatinine, blood urea nitrogen (BUN), total cholesterol (TC), triglycerides (TG), total protein (TP) and albumin were analyzed using fully automatic analyzer (Erba, Model-EM200).

All animals were subjected to gross necropsy at the end of the study duration. Organs and tissues were examined macroscopically and organ weight was recorded to calculate relative organ weight. Microscopic histopathological examination was carried out on the vital organs and tissues (such as liver, kidneys, heart, lungs, spleen, gonads (testes/ovaries) and gross lesions) of all animals in the control and high dose groups [11]. Organs / tissues were preserved in the neutral buffer formalin and subjected to histological examination as per standard protocols. 


\subsection{Statistical Analysis}

Data from the experiments was expressed as mean \pm standard error of mean (SEM). The mean difference between the control and treatment groups was analyzed by one-way Analysis of Variance using Graph Pad prism (version 5) Graph Pad Software, Inc., CA, USA. p value $<0.05$ was considered statistically significant.

\section{Results}

\subsection{Survival}

No post dose adverse effect was reported on survival of both male and female rats after oral administration of MJN for 90 consecutive days. No incidences of mortality were reported in MJN treated male and female rats at all tested dose levels. There were no incidence of any abnormal clinical signs based on clinical examination conducted at different time points in MJN treated animals at $500 \mathrm{mg} / \mathrm{kg}$ bw, $1000 \mathrm{mg} / \mathrm{kg}$ bw and $2000 \mathrm{mg} / \mathrm{kg}$ bw as compared to animals of control group.

\subsection{Body Weight}

There were no significant differences in body weight of MJN treated animals as compared to control group. The expected pattern of weight gain was observed in both male and female rats of drug treated group as compared to control group (Fig. 1 A, B).
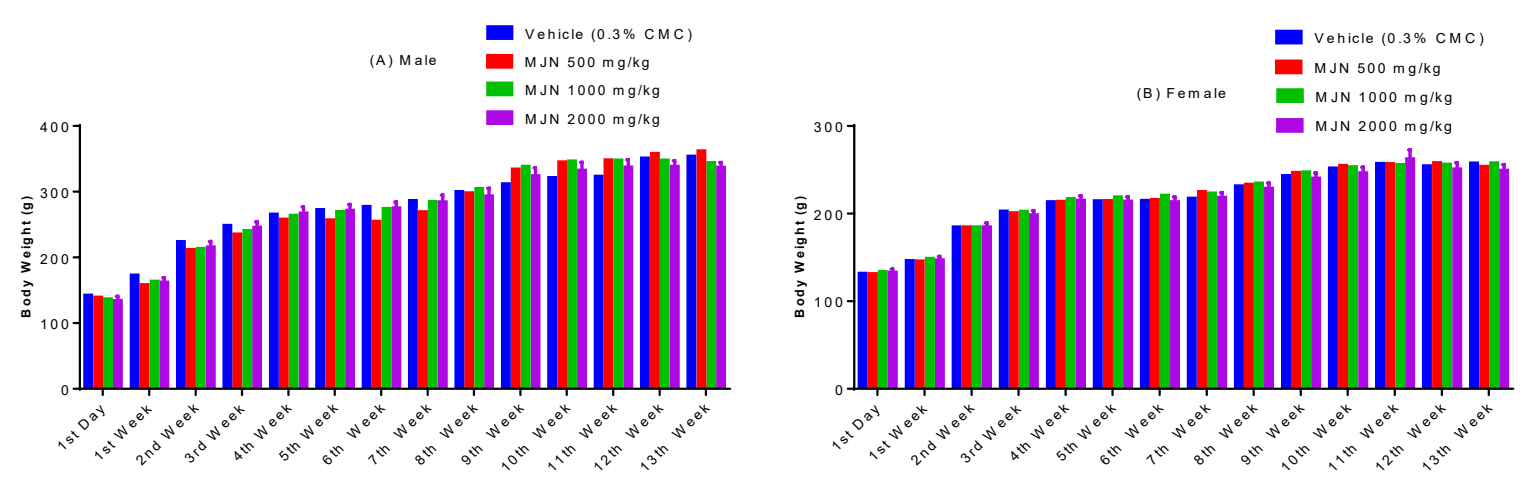

Fig. 1: Average body weight of control and MJN treated male (A) and female (B) rats

\subsection{Feed Consumption}

Feed intake was measured weekly throughout study duration. Male rats treated with MJN at all tested dose levels did not show significant difference in food consumption as compared to control group. Similarly, no consistent difference was observed in food consumption pattern in female group receiving test drug as compared to control group (Fig. 2 A, B).
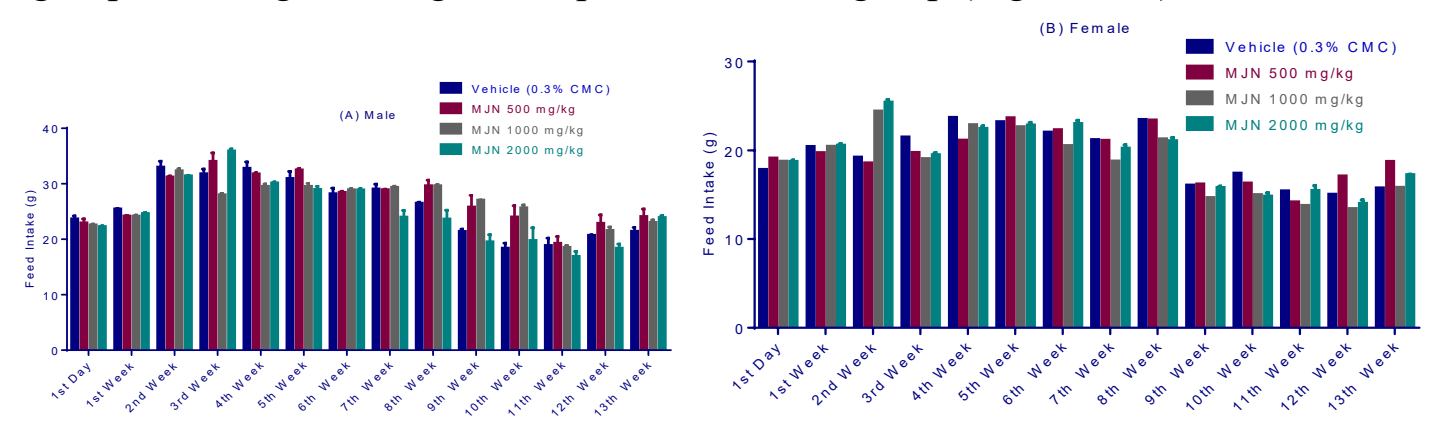

Fig. 2: Average feed intake of control and MJN treated Male (A) and Female (B) rats

\subsection{Rota Rod}

No significant difference was observed in the motor performance in Rota-rod among male and female MJN treated or control animals (Fig. 3 A, B). 

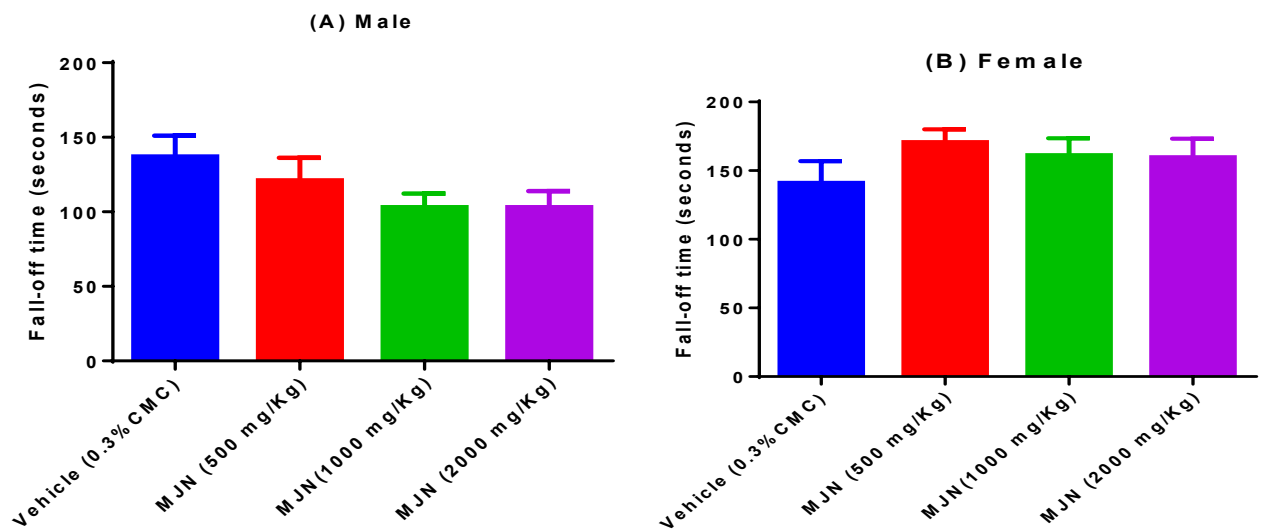

Fig. 3: Motor performance of control and MJN treated Male (A) and Female (B) rats

\subsection{Hematology}

The effect of MJN on haematological parameters in both male and female rats is listed in Table-1 A \& B. MJN did not produce any significant effect on haematological parameters after 90 days administration. Oral administration of MJN consecutively for 90 days did not produce any significant alterations in haematological parameters like $\mathrm{Hb}, \mathrm{RBC}$, WBC, HCT, platelates, neutrophils, lymphocytes, monocytes, basophils and eosinophils.

\subsection{Clinical Chemistry}

The effect of MJN on biochemical parameters in both male and female group of rats is listed in Table-2 A\& B. Administration of MJN did not produce any significant alteration in biochemical parameters in male rats such as serum glucose, AST, ALT, Bilirubin, ALP, BUN, creatinine, total cholesterol, triglycerides, HDL and LDL compared to control group. There was a significant increase $(\mathrm{p}<0.001)$ in serum total protein and globulin level in males at mid \& high dose level $(1000$ $\& 2000 \mathrm{mg} / \mathrm{kg} \mathrm{bw})$, significant increase in albumin at low dose $(\mathrm{p}<0.05)$ compared to control group. The level of serum sodium and calcium was significantly increased $(p<0.001)$ at mid and high dose group compared to control group. The level of serum potassium was significantly reduced at mid dose $(p<0.01)$ and high dose $(p<0.001)$ compared to control. Similarly, the level of chloride is significantly reduced in mid and high dose $(\mathrm{p}<0.001)$ compared to control group.

Oral administration of MJN did not produce any significant alteration in biochemical parameters in female rats such as serum glucose ALT, Total protein, albumin, serum uric acid, triglycerides, HDL and LDL, serum calcium and potassium level compared to control group. There was a significant reduction $(\mathrm{p}<0.001)$ in the AST at low and mid dose; significant reduction in Bilirubin at low dose $(\mathrm{p}<0.001)$; significant reduction in ALP at low dose $(\mathrm{p}<0.05)$ compared to control group. Serum BUN level was significantly decreased in MJN low and mid dose $(\mathrm{p}<0.001)$ and Creatinine level was significantly reduced in mid dose $(p<0.001)$ group compared to control group. A significant increase $(\mathrm{p}<0.05)$ in serum total cholesterol was observed in low dose level (500 mg/kg bw) compared to control group. The level of serum sodium was significantly decreased in low dose $(p<0.001)$ and increased in high dose group $(p<0.001)$ compared to control group. Serum chloride was significantly higher in low and mid dose $(p<0.001)$ compared to control group. 
Table 1A: Effect of MJN on Haematological Parameters of Male Rats

\begin{tabular}{|l|l|l|l|l|l|}
\hline \multicolumn{2}{|c|}{ Sex } & \multicolumn{5}{c|}{ Male (n=10) } \\
\hline \multicolumn{2}{|c|}{$\begin{array}{c}\text { Dose Levels } \\
(\mathbf{m g} / \mathbf{k g} \text { bw/day) }\end{array}$} & $\begin{array}{c}\text { Control } \\
\mathbf{( 0 . 3 \%} \mathbf{C M C})\end{array}$ & $\begin{array}{c}\text { MJN (500 } \\
\mathbf{m g} / \mathbf{k g})\end{array}$ & $\begin{array}{c}\text { MJN (1000 } \\
\mathbf{m g} / \mathbf{k g})\end{array}$ & $\begin{array}{c}\text { MJN (2000 } \\
\mathbf{m g} / \mathbf{k g})\end{array}$ \\
\hline Haemoglobin & $\mathrm{g} \%$ & $15.27 \pm 0.26$ & $15.33 \pm 0.113$ & $16.14 \pm 0.426$ & $16.16 \pm 0.217$ \\
\hline RBC & $\begin{array}{l}\text { Million/ } \\
\mathrm{mm} 3\end{array}$ & $8.050 \pm 0.12$ & $8.038 \pm 0.091$ & $8.478 \pm 0.217$ & $8.550 \pm 0.149$ \\
\hline WBC & $/ \mathrm{mm} 3$ & $10360 \pm 558.2$ & $8963 \pm 523.7$ & $9900 \pm 338.3$ & $9950 \pm 461.9$ \\
\hline Platelets & $\begin{array}{l}\text { Lakhs/ } \\
\mathrm{mm} 3\end{array}$ & $8.660 \pm 0.34$ & $8.55 \pm 0.417$ & $9.789 \pm 0.481$ & $8.850 \pm 0.510$ \\
\hline HCT & $\%$ & $41.20 \pm 0.63$ & $40.75 \pm 0.37$ & $43.44 \pm 1.24$ & $43.50 \pm 0.654$ \\
\hline Neutrophils & $\%$ & $6.30 \pm 0.895$ & $6.125 \pm 0.35$ & $5.444 \pm 1.12$ & $4.600 \pm 0.542$ \\
\hline Lymphocytes & $\%$ & $79.90 \pm 1.22$ & $79.13 \pm 0.74$ & $82.11 \pm 1.62$ & $83.50 \pm 1.176$ \\
\hline Eosinophils & $\%$ & $5.100 \pm 0.74$ & $5.750 \pm 0.45$ & $7.000 \pm 0.817$ & $5.900 \pm 0.586$ \\
\hline Monocytes & $\%$ & $5.900 \pm 1.02$ & $7.750 \pm 0.77$ & $4.556 \pm 0.766$ & $5.600 \pm 0.748$ \\
\hline
\end{tabular}

Values presented as mean $\pm \mathrm{SEM} ; \mathrm{n}=10$; One way ANOVA; No statistically significant difference compared to control.

Table 1B: Effect of MJN on Haematological Parameters of Female Rats

\begin{tabular}{|l|l|l|l|l|l|}
\hline \multicolumn{2}{|c|}{ Sex } & \multicolumn{4}{c|}{ Female (n=10) } \\
\hline \multicolumn{1}{|c|}{$\begin{array}{c}\text { Daily Dose } \\
\text { (mg/kg bw/day) }\end{array}$} & $\begin{array}{c}\text { Control } \\
(\mathbf{0 . 3 \%} \text { CMC) }\end{array}$ & $\begin{array}{c}\text { MJN (500 } \\
\text { mg/kg) }\end{array}$ & $\begin{array}{c}\text { MJN (1000 } \\
\text { mg/kg) }\end{array}$ & $\begin{array}{c}\text { MJN (2000 } \\
\text { mg/kg) }\end{array}$ \\
\hline Haemoglobin & g \% & $14.29 \pm 0.555$ & $15.18 \pm 0.271$ & $15.16 \pm 0.213$ & $14.38 \pm 0.152$ \\
\hline RBC & Million/mm3 & $7.40 \pm 0.300$ & $7.90 \pm 0.134$ & $7.86 \pm 0.096$ & $7.46 \pm 0.085$ \\
\hline WBC & $/ \mathrm{mm3}$ & $7690 \pm 857.4$ & $5170 \pm 179.5 *$ & $5720 \pm 544.0$ & $5680 \pm 301.4$ \\
\hline Platelets & Lakhs/mm3 & $7.870 \pm 0.234$ & $8.57 \pm 0.447$ & $8.600 \pm 0.227$ & $8.88 \pm 0.361$ \\
\hline HCT & $\%$ & $38.0 \pm 1.520$ & $40.0 \pm 0.760$ & $39.90 \pm 0.567$ & $38.20 \pm 0.490$ \\
\hline Neutrophils & $\%$ & $5.00 \pm 0.596$ & $6.80 \pm 0.646$ & $5.70 \pm 0.746$ & $3.90 \pm 0.348$ \\
\hline lymphocytes & $\%$ & $81.20 \pm 1.041$ & $79.30 \pm 1.065$ & $74.80 \pm 7.514$ & $85.70 \pm 0.967$ \\
\hline Eosinophils & $\%$ & $5.70 \pm 0.559$ & $5.20 \pm 0.327$ & $4.70 \pm 0.300$ & $5.30 \pm 0.423$ \\
\hline Monocytes & $\%$ & $7.10 \pm 0.809$ & $8.40 \pm 0.452$ & $7.60 \pm 0.476$ & $5.10 \pm 0.586$ \\
\hline
\end{tabular}

Values presented as mean $\pm \mathrm{SEM} ; \mathrm{n}=10$; One way ANOVA; $*=\mathrm{p}<0.05$ compared to control 
Table 2A: Effect of MJN on Biochemistry Parameters of Male Rats

\begin{tabular}{|c|c|c|c|c|}
\hline $\begin{array}{l}\text { Parameter } \\
\text { (Male) }\end{array}$ & $\begin{array}{l}\text { Vehicle } \\
(0.3 \% \text { CMC) }\end{array}$ & $\begin{array}{l}\text { MJN } \\
(500 \mathrm{mg} / \mathrm{kg})\end{array}$ & $\begin{array}{l}\text { MJN } \\
(1000 \mathrm{mg} / \mathrm{kg})\end{array}$ & $\begin{array}{l}\text { MJN } \\
(2000 \mathrm{mg} / \mathrm{kg})\end{array}$ \\
\hline Glucose (mg/dl) & $79.40 \pm 85.60$ & $72.25 \pm 4.395$ & $89.56 \pm 2.814$ & $85.60 \pm 4.799$ \\
\hline AST (IU/L) & $79.40 \pm 5.831$ & $72.25 \pm 4.395$ & $89.56 \pm 2.814$ & $85.60 \pm 4.799$ \\
\hline ALT (IU/L) & $62.50 \pm 4.349$ & $62.13 \pm 3.705$ & $50.56 \pm 6.466$ & $53.10 \pm 5.906$ \\
\hline Bilirubin $(\mathrm{mg} / \mathrm{dL})$ & $0.172 \pm 0.015$ & $0.159 \pm 0.012$ & $0.181 \pm 0.006$ & $0.171 \pm 0.007$ \\
\hline ALP (IU/L) & $65.50 \pm 9.952$ & $54.88 \pm 3.303$ & $52.22 \pm 2.222$ & $62.50 \pm 2.697$ \\
\hline Total Protein $(\mathrm{g} / \mathrm{dL})$ & $6.03 \pm 0.09894$ & $6.350 \pm 0.09636$ & $6.81 \pm 0.084 * * *$ & $7.11 \pm 0.091 * * *$ \\
\hline Albumin $(\mathrm{g} / \mathrm{dL})$ & $3.790 \pm 0.1027$ & $4.175 \pm 0.1013^{*}$ & $3.856 \pm 0.07286$ & $4.03 \pm 0.0857$ \\
\hline Globulin $(\mathrm{g} / \mathrm{dL})$ & $2.240 \pm 0.1477$ & $2.175 \pm 0.08399$ & $2.956 \pm 0.128^{* * *}$ & $3.00 \pm 0.098 * * *$ \\
\hline $\mathrm{AL} / \mathrm{Gb}$ ratio & $1.710 \pm 0.1320$ & $1.888 \pm 0.1172$ & $1.289 \pm 0.08240 *$ & $1.289 \pm 0.0824 *$ \\
\hline BUN (mg/dL) & $19.86 \pm 1.401$ & $18.68 \pm 1.731$ & $23.39 \pm 1.132$ & $23.88 \pm 1.203$ \\
\hline Creatinine $(\mathrm{mg} / \mathrm{dL})$ & $0.676 \pm 0.0128$ & $0.6525 \pm 0.01971$ & $0.692 \pm 0.0138$ & $0.691 \pm 0.0097$ \\
\hline Uric Acid (mg/dL) & $1.280 \pm 0.051$ & $1.325 \pm 0.1082$ & $1.567 \pm 0.057$ & $1.40 \pm 0.0650$ \\
\hline Cholesterol(mg/dl) & $91.20 \pm 2.384$ & $91.13 \pm 3.866$ & $91.00 \pm 4.673$ & $88.80 \pm 5.27$ \\
\hline Triglycerides $(\mathrm{mg} / \mathrm{dl})$ & $99.30 \pm 8.615$ & $80.75 \pm 8.404$ & $103.1 \pm 8.558$ & $118.2 \pm 7.287$ \\
\hline $\begin{array}{l}\text { HDL } \\
\text { Cholesterol(mg/dl) }\end{array}$ & $57.80 \pm 0.9752$ & $61.50 \pm 2.398$ & $61.00 \pm 2.640$ & $60.40 \pm 3.301$ \\
\hline $\begin{array}{l}\text { LDL } \\
\text { Cholesterol(mg/dl) }\end{array}$ & $13.50 \pm 2.979$ & $13.50 \pm 2.027$ & $11.44 \pm 3.697$ & $8.500 \pm 1.822$ \\
\hline Sodium (mmol/L) & $146.3 \pm 0.4230$ & $147.4 \pm 1.034$ & $153.8 \pm 0.323 * * *$ & $155.8 \pm 0.489 * * *$ \\
\hline Calcium $(\mathrm{mmol} / \mathrm{L})$ & $2.00 \pm 0.03651$ & $1.975 \pm 0.04532$ & $2.233 \pm 0.025^{* * *}$ & $2.24 \pm 0.023 * * *$ \\
\hline Potassium $(\mathrm{mmol} / \mathrm{L})$ & $5.690 \pm 0.1929$ & $5.475 \pm 0.1098$ & $5.067 \pm 0.071 * *$ & $4.880 \pm 0.079 * * *$ \\
\hline Chloride (mmol/L) & $105.9 \pm 0.7063$ & $106.6 \pm 1.569$ & $97.44 \pm 0.647 * * *$ & $98.00 \pm 0.73 * * *$ \\
\hline
\end{tabular}

Table 2B: Effect of MJN on Biochemistry Parameters of Female Rats

\begin{tabular}{|l|l|l|l|l|}
\hline $\begin{array}{l}\text { Parameter } \\
\text { (Female) }\end{array}$ & Vehicle $(0.3 \% \mathrm{CMC})$ & $\begin{array}{l}\text { MJN } \\
(500 \mathrm{mg} / \mathrm{kg})\end{array}$ & $\begin{array}{l}\text { MJN } \\
(1000 \mathrm{mg} / \mathrm{kg})\end{array}$ & $\begin{array}{l}\text { MJN } \\
(2000 \mathrm{mg} / \mathrm{kg})\end{array}$ \\
\hline Glucose $(\mathrm{mg} / \mathrm{dl})$ & $89.60 \pm 2.473$ & $91.80 \pm 5.401$ & $89.20 \pm 5.011$ & $77.50 \pm 3.525$ \\
\hline AST $(\mathrm{IU} / \mathrm{L})$ & $124.8 \pm 3.864$ & $94.60 \pm 2.638^{* * *}$ & $87.40 \pm 2.315^{* * *}$ & $113.2 \pm 5.360$ \\
\hline ALT $(\mathrm{IU} / \mathrm{L})$ & $48.40 \pm 2.841$ & $44.50 \pm 2.217$ & $38.90 \pm 2.614$ & $46.00 \pm 5.220$ \\
\hline Bilirubin $(\mathrm{mg} / \mathrm{dL})$ & $0.2610 \pm 0.02052$ & $0.131 \pm 0.006^{* *}$ & $0.264 \pm 0.037$ & $0.244 \pm 0.011$ \\
\hline ALP $(\mathrm{IU} / \mathrm{L})$ & $42.10 \pm 3.143$ & $31.60 \pm 3.143^{*}$ & $38.60 \pm 2.237$ & $37.60 \pm 2.737$ \\
\hline Total Protein $(\mathrm{g} / \mathrm{dL})$ & $6.800 \pm 0.1282$ & $6.760 \pm 0.1258$ & $6.920 \pm 0.2043$ & $7.210 \pm 0.1206$ \\
\hline Albumin $(\mathrm{g} / \mathrm{dL})$ & $4.230 \pm 0.09195$ & $4.140 \pm 0.07630$ & $4.140 \pm 0.08138$ & $4.120 \pm 0.1009$ \\
\hline Globulin $(\mathrm{g} / \mathrm{dL})$ & $2.590 \pm 0.1149$ & $2.620 \pm 0.1645$ & $2.600 \pm 0.1483$ & $3.190 \pm 0.0379^{* *}$ \\
\hline AL/Gb ratio & $1.700 \pm 0.1256$ & $1.630 \pm 0.1713$ & $1.650 \pm 0.1078$ & $1.250 \pm 0.04282$ \\
\hline BUN $(\mathrm{mg} / \mathrm{dL})$ & $25.78 \pm 0.9620$ & $17.46 \pm 0.765^{* * *}$ & $19.47 \pm 0.852^{* * *}$ & $22.83 \pm 1.017$ \\
\hline Creatinine $(\mathrm{mg} / \mathrm{dL})$ & $0.8270 \pm 0.01674$ & $0.7850 \pm 0.016$ & $0.7530 \pm 0.0129^{* *}$ & $0.809 \pm 0.01545$ \\
\hline Uric Acid $(\mathrm{mg} / \mathrm{dL})$ & $1.890 \pm 0.06574$ & $2.050 \pm 0.1565$ & $1.850 \pm 0.1241$ & $1.890 \pm 0.08090$ \\
\hline Cholesterol(mg/dl) & $73.40 \pm 3.500$ & $90.40 \pm 3.60^{*}$ & $87.10 \pm 4.629$ & $85.30 \pm 5.596$ \\
\hline Triglycerides(mg/dl) & $105.5 \pm 12.86$ & $128.0 \pm 9.691$ & $138.9 \pm 12.30$ & $132.0 \pm 12.59$ \\
\hline $\begin{array}{l}\text { HDL } \\
\text { Cholesterol(mg/dl) }\end{array}$ & $50.90 \pm 1.871$ & $60.40 \pm 2.12$ & $61.00 \pm 3.406$ & $58.20 \pm 3.200$ \\
\hline $\begin{array}{l}\text { LDL } \\
\text { Cholesterol(mg/dl) }\end{array}$ & $7.167 \pm 3.851$ & $6.500 \pm 1.773$ & $4.000 \pm 1.291$ & $10.25 \pm 2.780$ \\
\hline Sodium $(\mathrm{mmol} / \mathrm{L})$ & $145.3 \pm 0.6333$ & $136.7 \pm 0.775^{* * *}$ & $144.9 \pm 0.2333$ & $149.0 \pm 0.558^{* * *}$ \\
\hline Calcium $(\mathrm{mmol} / \mathrm{L})$ & $2.100 \pm 0.02981$ & $2.020 \pm 0.1153$ & $2.110 \pm 0.02333$ & $2.080 \pm 0.0200$ \\
\hline Potassium $(\mathrm{mmol} / \mathrm{L})$ & $4.280 \pm 0.03266$ & $7.810 \pm 3.689$ & $4.080 \pm 0.04422$ & $4.310 \pm 0.05667$ \\
\hline Chloride $(\mathrm{mmol} / \mathrm{L})$ & $104.5 \pm 0.4534$ & $107.3 \pm 0.651^{* * *}$ & $107.8 \pm 0.416^{* * *}$ & $103.0 \pm 0.2981$ \\
\hline
\end{tabular}

Values presented as mean \pm SEM; $\mathrm{n}=10$; One way ANOVA; $*=\mathrm{p}<0.05, * *=\mathrm{p}<0.01 ; * * *=\mathrm{p}<0.001$ compared to control. 


\subsection{Organ Weights}

MJN did not induce any alterations in final absolute organ weights and relative organ weight in the organ/tissues such as Brain, Heart, Lungs, Liver, Kidney, and Gonads (testes/ovaries and uterus). However, there was a significant decrease $(p<0.05)$ in relative weight of spleen in male group at mid and high dose levels as compared to control animals. There was a significant increase $(\mathrm{p}<0.01)$ in relative weight of right kidney in female group only at mid dose level $(1000 \mathrm{mg} / \mathrm{kg} \mathrm{bw})$ as compared to control group (Fig. 4 A \& B).

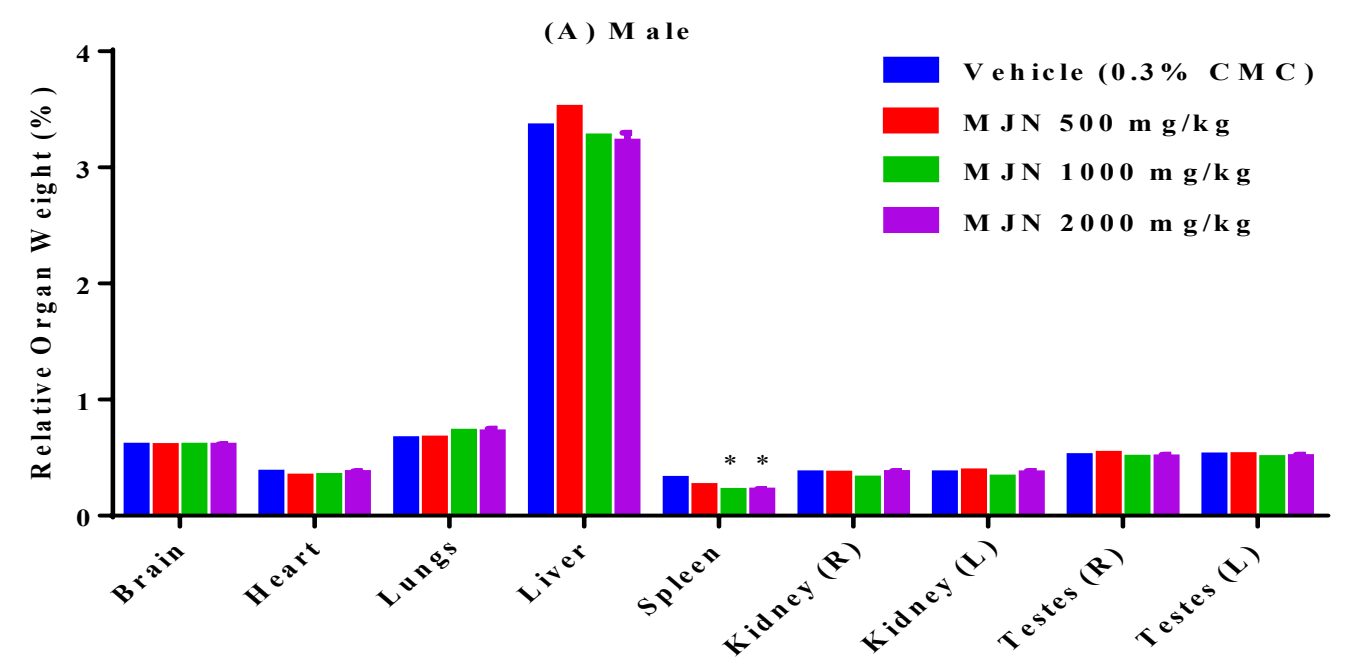

Fig. 4A: Relative Organ Weight Data of Male Rats

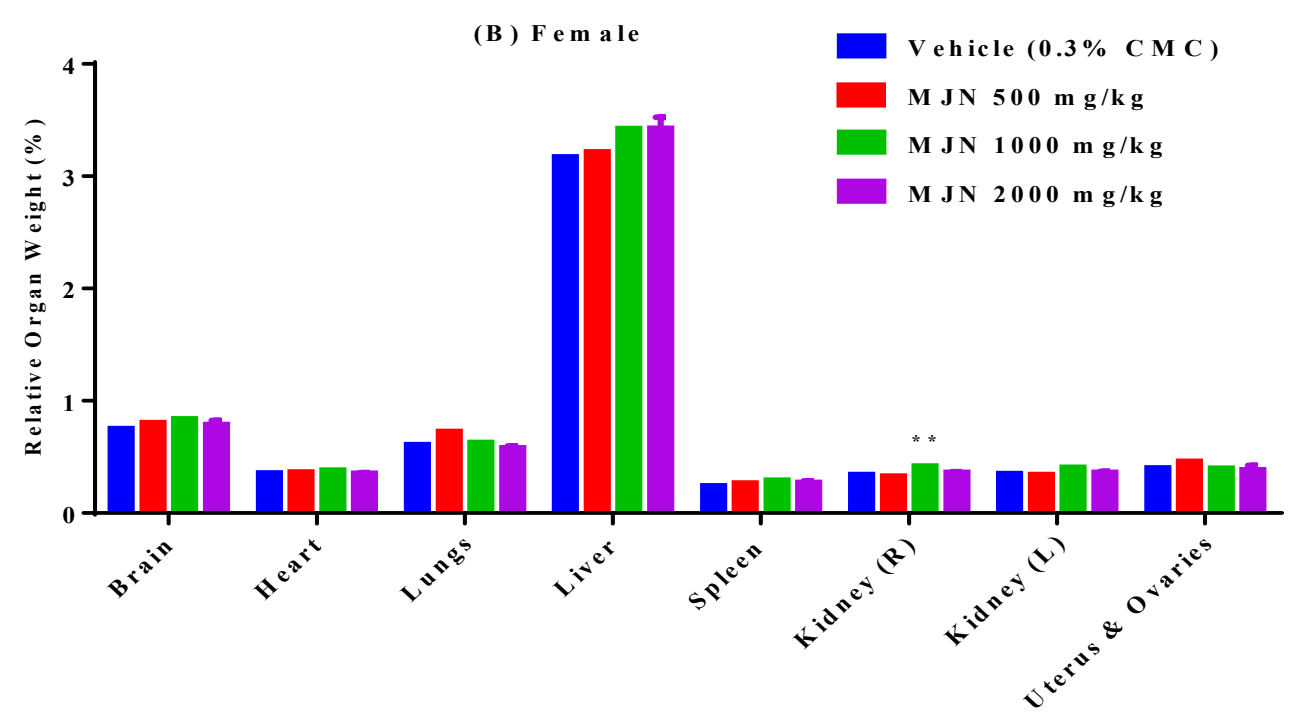

Fig. 4B: Relative Organ Weight Data of Female Rats; ${ }^{* *}=\mathrm{p}<0.01$ vs control

\subsection{Histopathology}

Minor changes observed in the organs like lungs, liver and kidneys were present across all groups including vehicle control group, hence cannot be considered toxicologically significant and do not appear to be related to the test compound administration while rest of the organs appeared normal during histological investigation (Fig. 5-A \& B). 


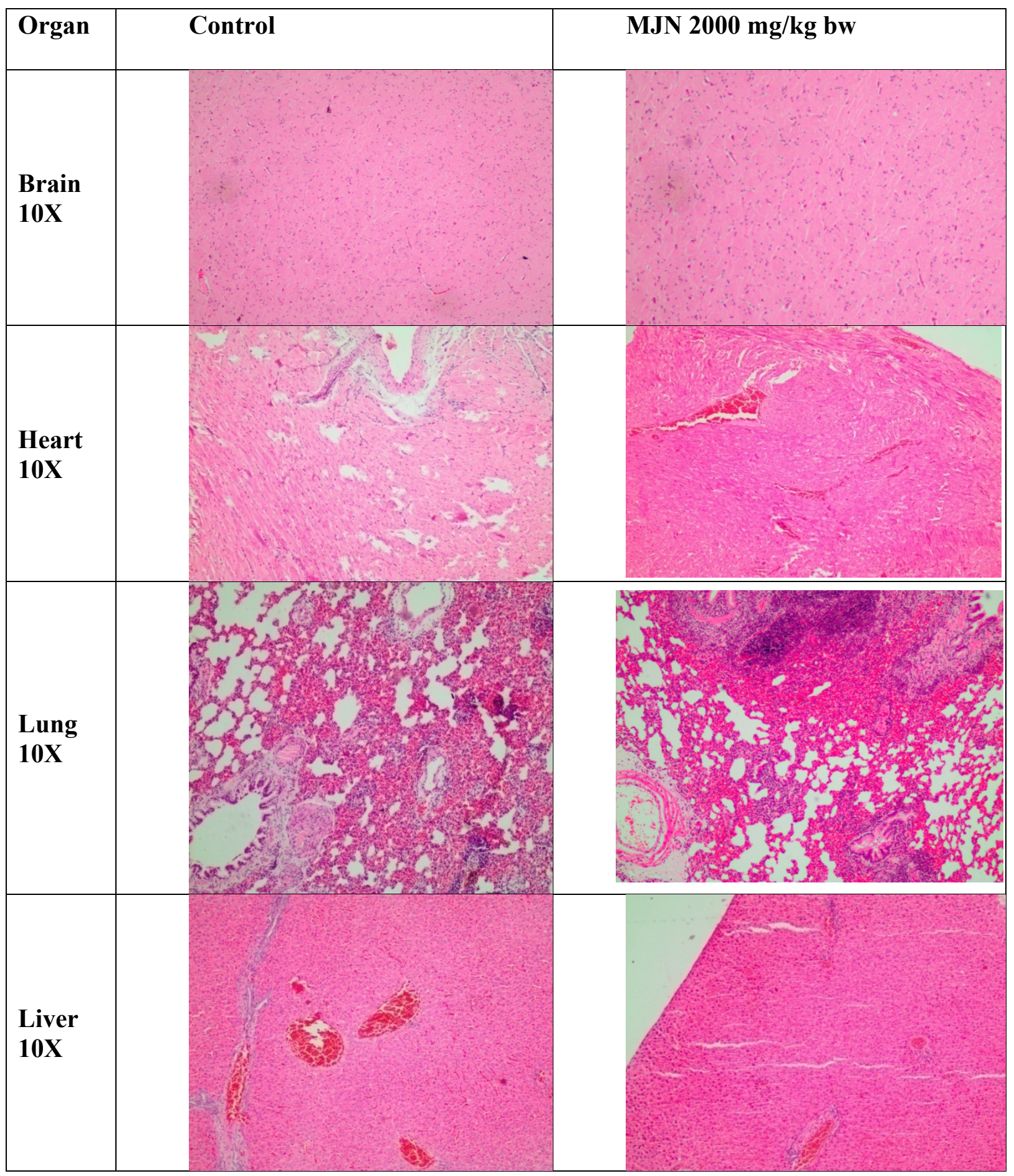

Fig. 5A: Representative histopathological organ section of control and high dose group of MJN 


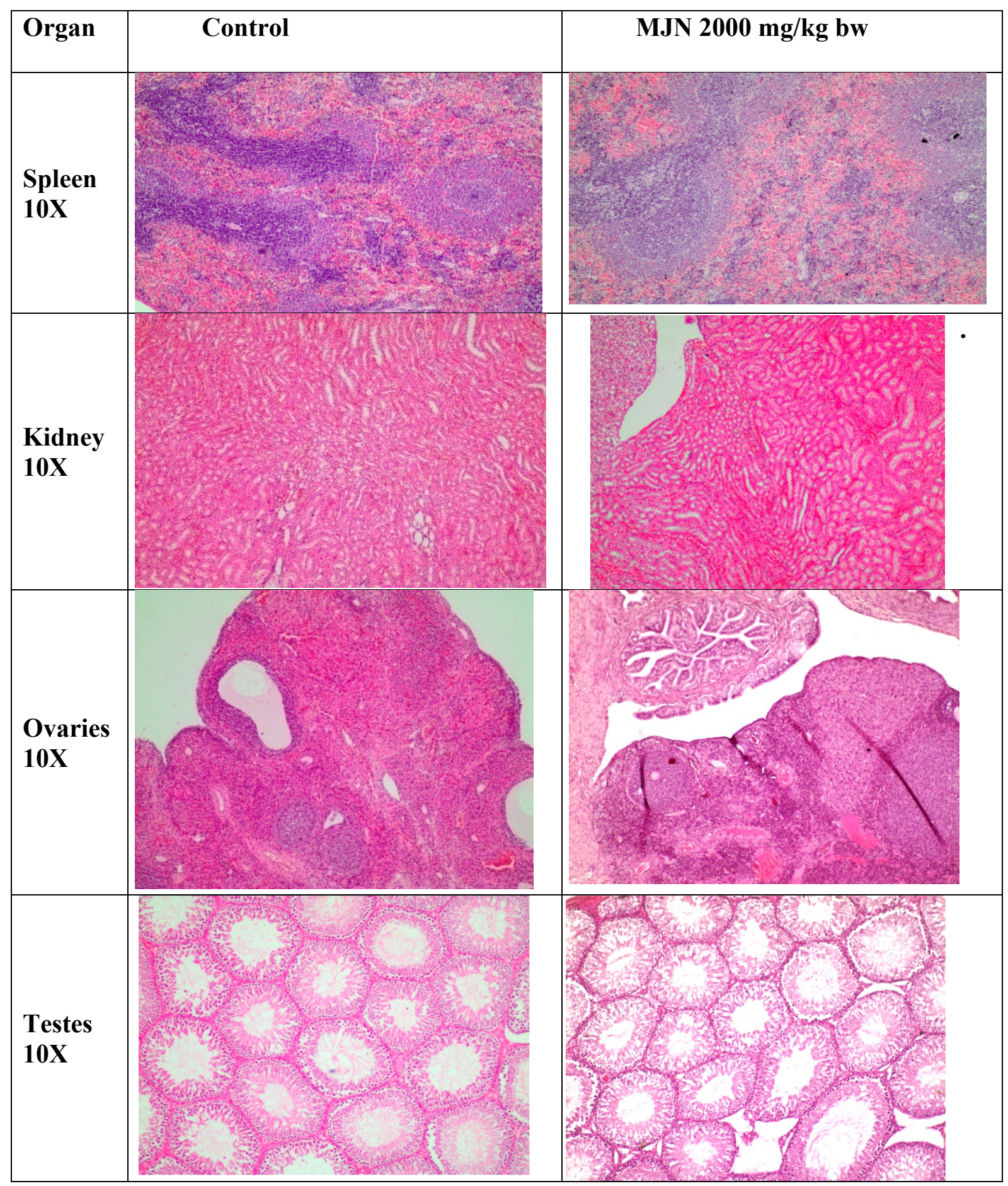

Fig. 5B: Representative histopathological organ section of control and high dose group of MJN

\section{Discussion}

The foremost challenge for scientific personnel involved in research on herbal medicine is to identify the toxic/adverse effect of herbal based pharmaceutical products. Inadequate standardization and contamination are the possible reason for herbal drug toxicity [12]. The percentage of herbal products is less than $10 \%$ in the world market which are truly standardize otherwise, the majority of these products are in clinical use with little knowledge about their active and /or toxic constituents [13]. Hence, the present study was designed to evaluate safety of MJN in rats.

In 90-days repeated dose oral toxicity study, no incidence of mortality and no clinical sign/symptom indicative of general systemic toxicity were observed during the study duration. The pattern of body weight gain measured weekly throughout the study duration was comparable to 
normal control group at all dose levels showed consistent normal growth. The feed consumption was measured weekly throughout study duration. Male rats treated with MJN at all tested dose levels showed no significant alteration in food intake as compared to control group. No difference was observed in food consumption in female group receiving test drug MJN compared to control group.

Hematopoietic system, especially the bone marrow where the production of red blood cell occurs is at major target for toxic agents. Hematopoietic system is the primary tissue hierarchical system where matured cells having limited life span get replaced by the new one. It is one of the most sensitive target organs for toxicity testing in animals [14]. Based on haematological tests, most of the parameters like $\mathrm{Hb}, \mathrm{RBC}, \mathrm{WBC}$, PLT Count and HCT in MJN treated group (male as well as female) were found comparable to control and values are within normal physiological limits, indicating lack of toxicity potential to hematopoietic system.

Biochemical parameters are important indicators to assess the integrity and functionality of organs and organ systems. Biomarkers are also important to assess risk, pathological condition and general health status of body [15] Based on biochemical results observed in present study, no significant alterations were observed with respect to different biomarkers of kidney and liver functions except certain isolated / incidental changes. Albumin, globulin and total protein level were increased in MJN treated male group. However, alteration in these parameters may not be considered toxicologically significant as the observed values remains within normal range. One of the possible causes for increase plasma total proteins is dehydration however; the assay of total proteins could not reveal clarity in reference to metabolic state of an individual [16]. Moreover, the rise in proteins levels in present study was found within normal physiological range. The effects observed were not dose dependent and could not be considered toxicologically significant.

Hepatotoxicity is a major concern and cause of attrition in drug development or restricted use after marketing [17]. As per European Medicines Agency, one of the most frequent reasons for the withdrawal from the market of an approved drug is liver toxicity [18]. Liver plays a central role in the drug metabolism which makes it highly susceptible to the adverse and toxic effects of drugs. Liver injury is diagnosed by measuring biomarkers like ALT, AST, ALP and bilirubin [19]. Elevations in serum enzyme levels are taken as the relevant indicators of hepatotoxicity whereas rise in both total and conjugated Bilirubin levels are indicative of overall liver function. Raised serum values of ALT and AST, in combination with increased Bilirubin levels, are considered to be the most relevant signal of liver toxicity [18]. Any elevation in ALT and AST indicate their outflow into the blood stream due to damage in the liver parenchymal cells [18-20]. In the present investigation, the parameters of liver functions were not adversely altered by MJN treatment which indicates that MJN did not affect liver function or metabolism.

Drug-induced renal injury is also common now a day and also critical in drug development [21]. The vital role of the kidney in drug excretion and detoxification makes it one of the major organs evoking drug-related toxic responses and an important target of toxicological studies. The standard parameters in preclinical or clinical trials for the detection and monitoring of renal function are serum Creatinine and BUN [21]. In the present study, no treatment related changes were observed in the serum Creatinine or BUN (in fact level of BUN and Creatinine is decreased in some MJN treated groups compared to control), suggesting that MJN is non-toxic to renal function. Further, the serum electrolyte levels were found to be well within the normal range of rats which reflects that MJN has no adverse effect on electrolyte homeostasis.

Motor coordination has traditionally been assessed in rodents by the rota-rod test, in which the animal is placed on a horizontal rod that rotates about its long axis; the animal must walk forwards to remain upright and not fall off [22]. Muscular strength or neuromuscular function in rodents may be influenced by sedatives, muscle relaxants as well as by toxic substances [23, 24]. In the present study, the performance of MJN treated rats was found comparable to the vehicle treated rats in rota-rod, indicating absence of any toxic effect of MJN on motor coordination.

Evaluation of organ/body weight ratios is recommended by the Society of Toxicological Pathology in toxicity studies lasting from 7 days to one year [25]. Relative organ weight data of 
MJN treated male and female rats at the end of 90 days dosing period were comparable with respective control groups except a significant increase in relative organ weight of right kidney in female group only at mid dose level and decrease in relative spleen weight in male group at mid and high dose levels. Since these changes are not dose dependant therefore may not be treatment related. No noteworthy findings were observed during gross necropsy in any organ/tissue in MJN treated or control animals. Further, no toxicologically relevant effects were observed in the histopathology of organs like Brain, Heart, Spleen, Testes and Ovary in any treatment group or control. Minor changes observed in lungs, liver and kidneys were present across all groups including vehicle control group and also not associated with alteration in biochemical parameters, hence may not be toxicologically relevant.

\section{Conclusions}

90-days repeated dose oral toxicity study was conducted in rats as per OECD guideline-408 at the dose levels of 500, 1000 and $2000 \mathrm{mg} / \mathrm{kg}$ bw/day of MJN. No incidence of mortality, adverse changes in clinical signs of toxicity or body weight gain of rats was noted. No toxicologically significant changes in hematology, clinical chemistry, and relative organ weights were observed in any MJN treated group or control animals. Gross pathology and histological investigation did not reveal any treatment-related abnormalities. Taken together, No-Observed-Adverse-Effect-Level (NOAEL) may be considered greater than $2000 \mathrm{mg} / \mathrm{kg}$ body weight in rats.

\section{Conflict of Interest}

Authors declare no conflicts of interests.

\section{Acknowledgments}

Authors are thankful to Central Council for Research in Unani Medicine (CCRUM), New Delhi (Under Ministry of AYUSH, Government of India) for funding the study. Authors are grateful to Prof. Asim Ali Khan, Director General-CCRUM, for support and guidance.

\section{References}

[1] Consumer Reports; Drug effectiveness Review Project (May 2012). "Evaluating Prescription Drugs Used to treat, Alzheimer's disease Comparing Effectiveness, Safety, and Price. Consumer Reports: 2. Retrieved 1 May 2013."

[2] Anonymous, Standard Unani Medical Terminology, CCRUM, Dept. of AYUSH, New Delhi, April 2012; pp.184.

[3] Ahmad KR. Tarjuma Sharah Asbab, CCRUM, Dept. of AYUSH, New Delhi 2010; Vol-I, pp.172-85.

[4] Fatima S. et.al., Preventive, Promotive and Curative Aspects of Dementia in complementary medicine(Unani): Through-Black Box-Design, Int. J. of Herbal Medicine, 2017; 5(10):1-5.

[5] Anonymous, Qarabadeen-e-Majeedi, Hamdard Publication, 9th ed.1986; pp.397-98.

[6] HM, Kabeeruddin. Al-Qarabadeen, CCRUM, Ministry of AYUSH, New Delhi, 2006; pp.1134.

[7] Anonymous, Unani Pharmacopoeia of India, Dept. of AYUSH, Ministry of Health and Family Welfare, Govt. of India.,2010; part 2nd, Vol-II; pp.113-115.

[8] CPCSEA, Compendium of CPCSEA (2018). New Delhi: Committee for the Purpose of Control and Supervision of Experiments on Animals, Animal Welfare Division, Ministry of Environment, Forest \& Climate Change, Government of India, 2018. 
[9] Anonymous, Unani Pharmacopoeia of India, Dept. of AYUSH, Ministry of Health and Family Welfare, Govt. of India.,2010; part 2nd, Vol-II; pp.113-115.

[10] Reagan-Shaw, Nihal M, Ahmad N. Dose translation from animal to human studies revisited, FASEB J. 2008;22(3): pp.659-61.

[11] OECD guideline 408, Repeated Dose 90-day Oral Toxicity Study in Rodents, 1998.

[12] Gotmi Sharwan, Parag Jain, Ravindra Pandey, S.S.S. Toxicity profile of traditional herbal medicine. J. Ayu. Herb. Med. 2015;1, 81-90.

[13] Ifeoma, O., Oluwakanyinsol, S. Screening of Herbal Medicines for Potential Toxicities, New Insights into Toxicity and Drug Testing, Sivakumar Gowder, IntechOpen. 2013; DOI: $10.5772 / 54493$.

[14] Testa NG and Dexter TM. Long-term hematopoietic damage: concepts, approaches, and results relevant to the study of environmental toxins. Environ mental Health Perspective 1989 Jul; 82: 51-56.

[15] Lawal, B., Shittu, O.K., Oibiokpa, F.I., Mohammed, H., Umar, S.I., Haruna, G.M. Antimicrobial evaluation, acute and sub-acute toxicity studies of Allium sativum. J. Acute Dis. 2016; 5, 296-301.

[16] Saidu Y., Bilbis, L.S., Lawal, M., Isezuo S.A., Hassan, S.W., Abbas, A.Y. Acute and Subchronic Toxicity Studies of Crude Aqueous Extract of Albizzia chevalieri Harms (Leguminosae). Asian J. Biochem. 2007; 2, 224-236.

[17] Devarbhavi H. An Update on Drug-induced Liver Injury. Journal of Clinical and Experimental Hepatology. 2012; 2(3): 247-259.

[18] EMEA. Non-Clinical Guideline on Drug-Induced Hepatotoxicity. London, E14 4HB, UK: European Medicines Agency.2008; pp 1-16.

[19] Singh A BT, Sharma OP. Clinical Biochemistry of Hepatotoxicity. Journal of Clinical Toxicology. 2011;S4:001.

[20] Ramaswamy RS, Prathyusha N, Saranya R, Sumathy H, Mohanavalli KT, Priya RJ, et al. Acute toxicity and the 28-day repeated dose study of a Siddha medicine Nuna Kadugu in rats. BMC Complementary and Alternative Medicine 2012;12: 190.

[21] Fuchs TC, Hewitt P. Biomarkers for drug-induced renal damage and nephrotoxicity-an overview for applied toxicology. The AAPS Journal. 2011; 13(4): 615-631.

[22] Vincent Castagne CF-Ca, Elise Esneault, Hernier Anne Marie, Martine Lemaire, and Roger D. Porsolt. Rotarod Test. In: H. Gerhard Vogel JM, Franz J. Hock, Dieter Mayer (eds). Drug Discovery and Evaluation: Safety and Pharmacokinetic Assays, Second edn. Heidelberg Dordrecht London New York: Springer-Verlag. 2013; pp 29-30.

[23] Deacon RM. Measuring motor coordination in mice. Journal of Visualized Experiments : JoVE(75): e2609.2013.

[24] Vogel HG (ed). Drug Discovery and Evaluation: Pharmacological Assays. Springer-Verlag: Germany. 2008.

[25] Sellers RS, Morton D, Michael B, Roome N, Johnson JK, Yano BL, et al. Society of Toxicologic Pathology position paper: organ weight recommendations for toxicology studies. Toxicol Pathol. 2007;35:751-5. 